\title{
Predictive Biomarkers of Hepatocellular Carcinoma in Sudanese Patients with Liver Cirrhosis
}

\author{
Eman Kabbara ${ }^{1}$, Mudawi HM², Abdelraheem Osman Mohamed ${ }^{3}$, Abozer Y Elderdery ${ }^{5}$, Hamdan Z \\ Hamdan $^{1}$,Sayed Ibrahim Ali ${ }^{6}$, Ahmed Mohamedain Eltom ${ }^{3,4}$ \\ ${ }^{1}$ Department of Biochemistry, Faculty of Medicine, Al Neelain University, Sudan \\ ${ }^{2}$ Department of Internal Medicine, Faculty of Medicine, Khartoum University, Sudan \\ ${ }^{3}$ Department of Biochemistry, Faculty of Medicine, Khartoum University, Sudan \\ ${ }^{4}$ Department of Biomedical Sciences, College of Medicine, King Faisal University, Saudi Arabia \\ ${ }^{5}$ Department of Haematology, Faculty of Applied Medical Science, Aljouf University, Saudi Arabia. \\ ${ }^{6}$ Department of Family Medicine, College of Medicine, King Faisal University, Saudi Arabia
}

\begin{abstract}
Background: Liver cirrhosis (LC) is a prevalent condition in Sudan and the main predisposing factor for hepatocellular carcinoma (HCC). This study assesses the effectiveness of the use of $\alpha$-fetoprotein (AFP), ultrasound (US), AFPmRNA in addition liver enzymes as early predictors for hepatocellular carcinoma (HCC) in Sudanese patients with liver cirrhosis (LC). Methods: A Hundred patients with LC, 25 patients with confirmed HCC and 50 healthy controls were included in the study. Serum AFP, AFPmR NA and liver enzymes were determined annually in patients with liver cirrhosis in addition to abdominal U/S for 3 years. Serum AFP was determined using enzyme immunoassay (EIA) in patients and controls. Reverse transcriptase-polymerase chain reaction (RT-PCR) was used for detection of AFPmRNA. Results: During follow up hepatic nodules were identified in three liver cirrhotic patients (3\%). AFP detection rate was higher (64\%) at a low cut-off point (20ng/dl). the AFPmRNA had a very low sensitivity (24\%) in HCC group. Only 3 patients developed HCC additionally to LC after follow up and all had positive AFPmRNA and AFP. Conclusions: In conclusion the combination of U/S, AFP and AFPmRNA would be the most effective tool for HCC screening in Sudan. However, AFPmRNA alone had the lowest detection rate and is therefore not recommended for screening.
\end{abstract}

Keywords: hepatocellular carcinoma, $\alpha$-fetoprotein, AFPmRNA, ultrasound, liver cirrhosis, Sudan

\section{Introduction}

Hepatocellular carcinoma (HCC) occurs mostly on top of liver cirrhosis and chronic liver inflammatory conditions (1, 2 ). The geographic distribution of this cancer depends on the distribution of its predisposing factors like hepatitis B virus (HBV) and hepatitis $\mathrm{C}$ virus (HCV). These factors were reported to cause $57 \%$ and $78 \%$ of cirrhosis and HCC cases respectively worldwide (3).

$\mathrm{HBV}$ and aflatoxin B1 are the main causes of liver cirrhosis and HCC in Africa $(4,5)$. Alcohol consumption and nonalcoholic steato-hepatitis are contributing factors in developed countries (2). Other factors such as diabetes mellitus are more common in modern life and constitute risk factors for HCC (6). In Sudan HBV and aflatoxin in peanut butter are major risk factors for development of $\mathrm{HCC}$ as $80 \%$ of HCC cases could be caused by these two factors (7).

Early detection of HCC is important as it can improve the survival of patients (8). Currently the recommended screening strategy includes measurement of serum $\alpha$ fetoprotein (AFP) levels with abdominal ultrasound for the detection of $\mathrm{HCC}$ at an earlier stage (9). This strategy can increase the detection of HCC nodules three-fold and can decrease the number of deaths (10).

The extraction and detection of AFPmRNA from peripheral blood mononuclear cells by RT-PCR has been studied as molecular marker which may improve the effectiveness in screening of HCC patients for early metastasis (11).

The objectives of this study are to evaluate the use of AFP and AFPmRNA as early predictors of HCC in Sudanese patients with liver cirrhosis.

\section{Material and Methods}

This is a prospective case-control study carried out in National center for gastroenterology (Ibn sina hospital) in Khartoum, Sudan. The study population consisted of 100 patients with liver cirrhosis, 25 patients with hepatocellular carcinoma and 50 healthy controls. Both patients and controls were studied after obtaining informed consent. The patients with liver cirrhosis were $>20$ years according to recommendations of the American association for the study of liver diseases (AASLD)(12) and were followed up for 3 years. To be enrolled in liver cirrhosis group the patients were diagnosed on clinical findings, laboratory and radiological testing and were either being Child's grade A or B (patients with child's grade C were excluded). Hepatitis B and $\mathrm{C}$ viruses were diagnosed by testing patients' sera for hepatitis B surface antigen and hepatitis C antibody. The follow up included clinical examination and yearly measurement of liver enzymes, alpha-fetoprotein, ultrasound scanning for detection of early HCC nodules and AFP mRNA. All patients in the hepatocellular carcinoma group were developing carcinoma on top of liver cirrhosis, and all 


\section{International Journal of Science and Research (IJSR) \\ ISSN (Online): 2319-7064 \\ Index Copernicus Value (2013): 6.14 | Impact Factor (2015): 6.391}

were diagnosed according to AASLD (12).Liver enzymes (aspartate transaminase (AST), alanine transaminase (ALT), alkaline phosphatase (ALP), and gamma-glutamyltransferase (GGT) were measured following routine spectrophotometric methods. Serum Alpha fetoprotein (AFP) was measured using a one-step sandwich EIA. AFP mRNA was detected using heparinized whole blood from which plasma fraction was removed. The cellular fraction was enriched for mononuclear cells or possible tumor cells according to the method described by Komeda (13). RNA was extracted by Qiagen-RNeasy midi kit. Nested RT-PCR was conducted and samples were analyzed by electrophoresis on a $15 \%$ polyacrylamide gel and stained with ethidium bromide for the specific bands. The design of external and inner pairs of primers were taken from previous research as follows (14).

EX-sense 5'-ACTGAATCCACAACACTGCATAG-3'

EX-antisense 5'-TGCAGTCAATGCATCTTCACCA-3'

IN-sense 5'-TGGAATAGCTTCCATATTGGATTC-3'

IN-antisense 5'-AAGTGGCTCTTGAACAAACTGG-3'

According to the design of primer pairs, the PCR products of 174 and 101 base pairs were amplified from AFP cDNA by external and internal primer pairs, respectively. The locations of the primer pairs were as follows:EX-sense in exon 1 (AFP mRNA nucleotides 90-112), EX-antisense in exon 2 (AFP mRNA nucleotides 263-241), IN-sense over exon 1 and exon 2 (AFP mRNA nucleotides 122-145), IN-antisense in exon 3 (AFPmRNA nucleotides 222-200).

\section{Statistical Analysis}

Statistical analysis was performed with the Statistical Package for the Social Sciences (SPSS) software SPSS Inc., Chicago, IL, USA, version 13.0. The Data were tested statistically for normal distribution by (KolmogorovSmirnov \& Shapiro-Wilk) tests and were expressed as mean \pm standard deviation (SD) if normally distributed or median $\left(25^{\text {th }}-75^{\text {th }}\right.$ quartile) if it is abnormally distributed. Comparing between groups were assessed by Student's t-test or the Chisquare test for numerical and categorical data, respectively. Abnormally distributed numerical variables were compared by Mann-Whitney $U$ test. $\mathrm{P}<0.05$ was considered statistically significant.

\section{Results}

The general characteristics of the patients, 100 with liver cirrhosis, 25 with hepatocellular carcinoma and the 50 controls, are shown in table 1 . Most of patients with liver cirrhosis were males (78\%). The main cause of liver cirrhosis in this group was hepatitis B viral infection (42\%) followed by alcohol consumption (28\%) and HCV (6\%), Table 1.

Serum AFP, AFPmRNA and liver function test (ALT, AST, GGT, ALP, serum AFP)

Patients with hepato-cellular carcinoma were divided to two groups according to AFPmRNA status, positive or negative. AFPmRNA was not detected either in patients with liver cirrhosis nor normal control. In the hepatocellular carcinoma group, the middle quartiles $\left(25^{\text {th }}-75^{\text {th }}\right)$ of serum AFP was significantly higher in AFPmRNA positive compared to AFPmRNA negative group [1000.0 (648.3-1052) vs 36.2 (4.0-122.8) ng/ml, $P=<0.001]$, table 2. Although serum
ALT, AST, GGT, ALP and albumin were lower in patients with positive AFPmRNA compared to the negative group, the difference is not statistically significant.

Among patients with liver cirrhosis, significant raised levels of ALP were observed in patients with liver cirrhosis compared to normal control [31.5 (3.8) vs 7.52 (4.6) IU/, $P=$ 0.01]. There was a significant decrease during follow up of patients with LC in AST $(P<0.001)$, ALT $(P=0.004)$, and GGT $(P=0.002)$. However, ALP enzyme levels did not change significantly with time $(\mathrm{P}=0.210)$, (Table 2).

Most of Patients with hepatocellular carcinoma on top of liver cirrhosis were males $(68 \%)$, mainly in age group (>60yrs) $48 \%$; the predisposing factors were HBV (44\%) followed by alcohol consumption (20\%), then HCV (16\%).

An AFP cut off level $\geq 20 \mathrm{ng} / \mathrm{dl}$ was chosen in line with other studies (15); the detection rate by AFP for tumor among HCC group is $64 \%(16 / 25)$. The detection rate of AFPmRNA is only $24 \%$ in the HCC group. $66.7 \%$ of patients with HCC in whom AFPmRNA was detected were positive for $\mathrm{HBV}$.

AFPmRNA were detected in all three patients (3/100) who developed HCC additionally to liver cirrhosis during the follow-up period and they also have AFP > $20 \mathrm{ng} / \mathrm{dl}$. During the follow-up period, three patients died, none diagnosed as HCC. Figure 1 shows a typical run of AFPmRNA.

\section{Discussion}

Patients with liver cirrhosis were studied and followed up in this research, together with patients with HCC and healthy controls. The mean age of patients with LC was significantly different from patients with HCC, but not significantly different from healthy controls. This could be explained by the fact that HCC develops on top of LC after about 20-30 years of initial infection with HBV or HCV (16).

Hemoglobin levels were significantly lower in the HCC group compared to patients with LC. This could be due to the late presentation of patients with this cancer, which was certainly accompanied by loss of appetite and anemia due to chronic disease(17).

ALP was not significantly different between LC and HCC; however it is the only liver enzyme that carries a significant risk when it is above certain cut-off level, which is in agreement with Hann HW et al, who found that ALP was associated with increased risk for HCC in patients with LC (18).

According to the previous study GGT enzyme also had a significant relationship with increased HCC risk and there was also a significant association between GGT and overall cancer incidence (19). This contrasts with our study which showed no significant relationship and this goes with other study which showed no association with cancer mortality (20).It is important to notice that GGT levels could be affected by factors like diet, environmental pollutants and xenobiotic (19).

\section{Volume 5 Issue 6, June 2016 www.ijsr.net}

Licensed Under Creative Commons Attribution CC BY 


\section{International Journal of Science and Research (IJSR) \\ ISSN (Online): 2319-7064}

Index Copernicus Value (2013): 6.14 | Impact Factor (2015): 6.391

The main cause of Liver cirrhosis in this study was HBV, in agreement with another study which indicated that HBV is of high seroprevalence in Sudan (21). HCV infection was the third cause of LC in our patients, which is similar to results of a study carried out at the National Center for Gastrointestinal and Liver Disease in Khartoum, which concluded that HCV was of low seroprevalence (2.3\%)(22).

Alcohol consumption was found to be the second cause of liver cirrhosis among the group, with $28 \%$ of patients acknowledging intake of alcohol, which goes with other studies in countries like USA where alcohol consumption is very high and more common than hepatitis C (23).

AFPmRNA was not detected in any of patients with liver cirrhosis without HCC, which is similar to previous study conducted by Liu Y et al(14). However, it was detected only in six patients of hepatocellular carcinoma. This is comparable to other studies where AFPmRNA was detected in $13.3 \%, 13.6 \%, 43.8 \%$ patients with liver cirrhosis $(11,24$, 25) respectively. AFPmRNA was markedly expressed in HCC patients compared to patients without HCC (11).

Detection rate of $\mathrm{HCC}$ by AFP in this study was $64 \%$ which is in concordance with other studies where AFP detection rates range from 41 to $69 \%(8,26,27)$.
A close relationship exists between the expression of AFPmRNA and HCC development, and metastasis [30]. Using nested RT-PCR, AFPmRNA was detected in $24 \%$ of our patients with HCC. These results are similar to previous studies where AFPmRNA was detected in $25 \%$ of HCC cases (24), but is low compared to other results where the detection of AFPmRNA was ranged between $30 \%$ and $73.3 \%(11,28-32)$. The detection rate of AFPmRNA increased to $66.7 \%$ where AFP level were higher than $200 \mathrm{ng} / \mathrm{dl}$ and this represents the only significant relationship between the two biomarkers, which is in line with another study(28).

Most cases of HCC in whom AFPmRNA was detected were HBV seropositive $(66.7 \%)$ compared to a previous study which indicated no association between AFPmRNA and hepatitis B infection (14). This is probably due to the high seroprevalence of HBV in Sudan.

In conclusion, this study has shown that combination of AFP, AFPmRNA and U/S increases sensitivity for the detection of early HCC nodules rendering them the method of choice for diagnosis of $\mathrm{HCC}$ on top of cirrhosis. AFPmRNA alone carries a poor detection rate for the diagnosis of HCC.

Table 1: Demographic information of enrolled patients

\begin{tabular}{|l|c|c|c|c|c|c|}
\hline Group & $\begin{array}{c}\text { Sex } \\
\mathrm{M}(\%) / \mathrm{F}(\%)\end{array}$ & Age (range) & $\mathrm{HBV}^{+\mathrm{ve}}(\%)$ & $\mathrm{HCV}^{+\mathrm{ve}}(\%)$ & Alcoholic (\%) & No \\
\hline HC & $34(68) / 16(32)$ & $(37-58)$ & 0 & 0 & 0 & 50 \\
\hline HCC & $17(68) / 8(32)$ & $(47-70)$ & $11(44)$ & $4(16)$ & $5(20)$ & 25 \\
\hline LC & $78(78) / 22(22)$ & $(38-60)$ & $42(42)$ & $6(6)$ & $28(28)$ & 100 \\
\hline
\end{tabular}

Key: $\mathbf{M}=$ Male; $\mathbf{F}=$ Female $\mathbf{H C}=$ Healthy Control; $\mathbf{L C}=$ Liver Cirrhosis; $\mathbf{H C C}=$ Hepatocellular carcinoma $\mathbf{H B V}^{+\mathbf{v e}}=$ Positive HBV; $\mathbf{H C V}^{+\mathbf{v e}}=$ Positive $\mathrm{HCV}$

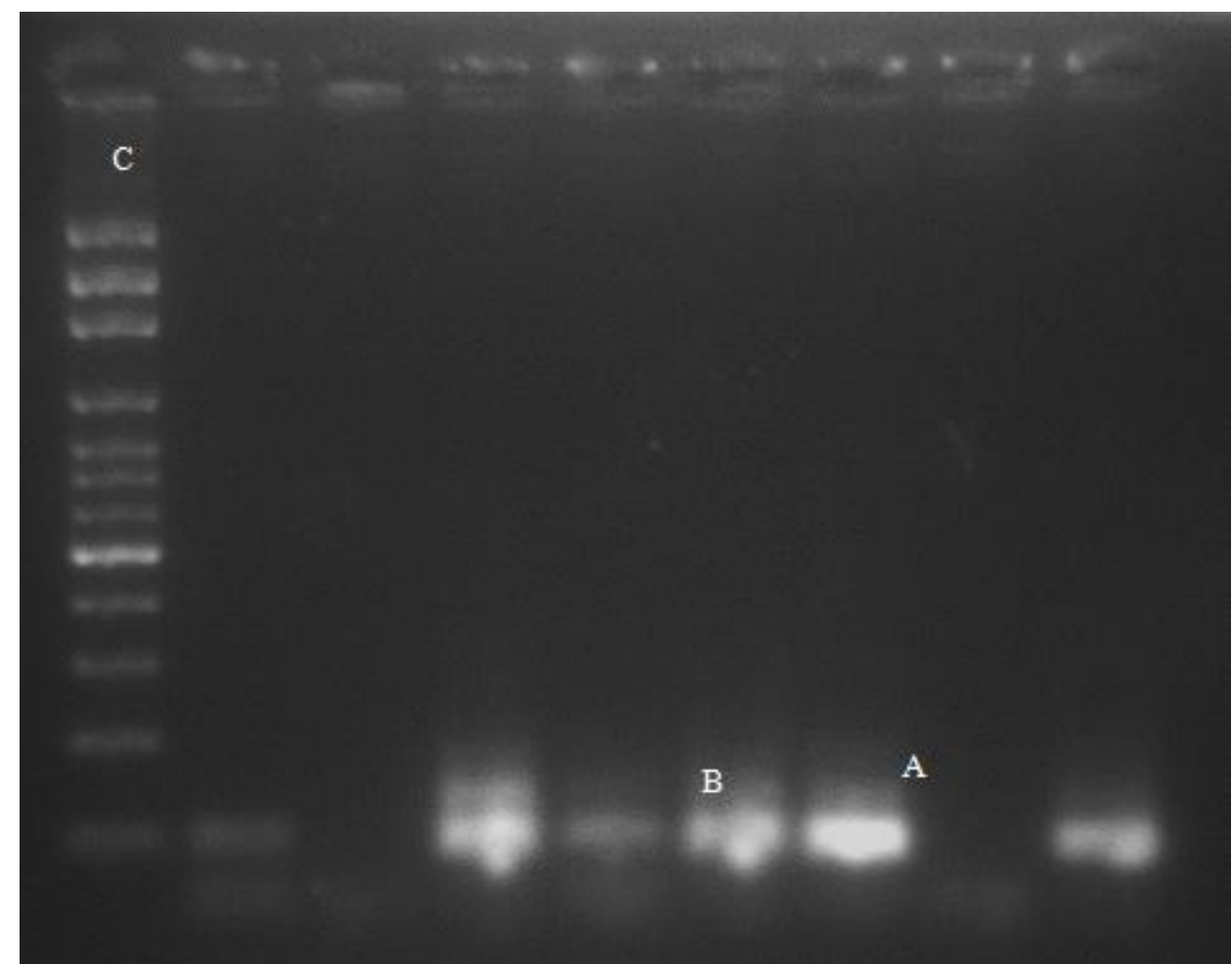

Figure 1: AFPmRNA detected in blood of patients with HCC. (PCR product (101 bp) of AFPcDNA using nested RT-PCR).

Key: A=Control Sample; B= AFPcDNA (101); C= DNA stepladder

\section{Volume 5 Issue 6, June 2016 www.ijsr.net}




\section{International Journal of Science and Research (IJSR) \\ ISSN (Online): 2319-7064}

Index Copernicus Value (2013): 6.14 | Impact Factor (2015): 6.391

Table 2: Results of liver function tests, AFP and haemoglobin (Can you use (SD) for AFP, please?)

\begin{tabular}{|l|c|c|c|c|c|c|c|}
\hline \multicolumn{1}{|c|}{ Groups } & Alb $( \pm$ SD $)$ & ALT $( \pm$ SD $)$ & AST $( \pm$ SD $)$ & GGT $( \pm$ SD $)$ & ALP $( \pm$ SD $)$ & AFP $( \pm$ SD $)$ & Hb $( \pm$ SD $)$ \\
\hline H C & $4.37(0.6)$ & $8.9(5.4)$ & $10.0(5.7)$ & $7.65(4.2)$ & $7.5(4.6)$ & $2.3(1.3-4.8)$ & $14.6(1.5)$ \\
\hline HCC $^{\text {+ve }}$ & $3.0(0.4)$ & $36.1(2.6)$ & $68.5(13.1)$ & $36.1(1.5)$ & $38.0(4.5)$ & $1000.0(648.3-1052)^{* *}$ & $9.7(2.2)$ \\
\hline HCC $^{- \text {-ve }}$ & $3.3(0.5)$ & $93.6(10.1)$ & $103.1(8.2)$ & $66.1(5.1)$ & $46.0(3.6)$ & $36.2(4.0-122.8)$ & $10.7(1.4)$ \\
\hline LC & $3.2(0.8)$ & $40.6(38.7)$ & $57.2(5.4)$ & $37.4(2.9)$ & $31.5(3.8)$ & $5.3(2.7-14.4)$ & $12.2(2.1)$ \\
\hline
\end{tabular}

Key: HC= Healthy Control; $\mathbf{L C}=$ Liver Cirrhosis; HCC = Hepatocellular carcinoma; Alb= Albumin; ALT = Alanine minotransferase; $\mathbf{A S T}=$ Aspartate aminotransferase; $\mathbf{G G T}=$ Gamma-glutamyl transferase; $\mathbf{A L P}=$ Alkaline phosphatase; $\mathbf{A F P}$ $=$ alpha fetoprotein $\mathbf{H} \mathbf{b}=$ Haemoglobin,

\section{References}

[1] El-Serag HB. Epidemiology of viral hepatitis and hepatocellular carcinoma. Gastroenterology. 2012 May;142(6):1264-73 e1.

[2] Ierardi E, Rosania R, Zotti M, Giorgio F, Prencipe S, Valle ND, et al. From chronic liver disorders to hepatocellular carcinoma: Molecular and genetic pathways. World J Gastrointest Oncol. 2010 Jun 15;2(6):259-64.

[3] Perz JF, Armstrong GL, Farrington LA, Hutin YJ, Bell BP. The contributions of hepatitis B virus and hepatitis $\mathrm{C}$ virus infections to cirrhosis and primary liver cancer worldwide. J Hepatol. 2006 Oct;45(4):529-38.

[4] Kramvis A, Kew MC. Epidemiology of hepatitis B virus in Africa, its genotypes and clinical associations of genotypes. Hepatol Res. 2007 Jul;37(s1):S9-S19.

[5] Kirk GD, Turner PC, Gong Y, Lesi OA, Mendy M, Goedert JJ, et al. Hepatocellular carcinoma and polymorphisms in carcinogen-metabolizing and DNA repair enzymes in a population with aflatoxin exposure and hepatitis B virus endemicity. Cancer Epidemiol Biomarkers Prev. 2005 Feb;14(2):373-9.

[6] Yang WS, Va P, Bray F, Gao S, Gao J, Li HL, et al. The role of pre-existing diabetes mellitus on hepatocellular carcinoma occurrence and prognosis: a meta-analysis of prospective cohort studies. PLoS One. 2011;6(12):e27326.

[7] Omer RE, Kuijsten A, Kadaru AM, Kok FJ, Idris MO, El Khidir IM, et al. Population-attributable risk of dietary aflatoxins and hepatitis B virus infection with respect to hepatocellular carcinoma. Nutr Cancer. 2004;48(1):15-21.

[8] Bolondi L, Sofia S, Siringo S, Gaiani S, Casali A, Zironi $\mathrm{G}$, et al. Surveillance programme of cirrhotic patients for early diagnosis and treatment of hepatocellular carcinoma: a cost effectiveness analysis. Gut. 2001 Feb;48(2):251-9.

[9] Saffroy R, Pham P, Reffas M, Takka M, Lemoine A, Debuire B. New perspectives and strategy research biomarkers for hepatocellular carcinoma. Clin Chem Lab Med. 2007;45(9):1169-79.

[10] Thompson Coon J, Rogers G, Hewson P, Wright D, Anderson R, Cramp M, et al. Surveillance of cirrhosis for hepatocellular carcinoma: systematic review and economic analysis. Health Technol Assess. 2007 Sep;11(34):1-206.

[11] Yao F, Guo JM, Xu CF, Lou YL, Xiao BX, Zhou WH, et al. Detecting AFP mRNA in peripheral blood of the patients with hepatocellular carcinoma, liver cirrhosis and hepatitis. Clin Chim Acta. 2005 Nov;361(1-2):11927.
[12] Boyer TD, Haskal ZJ. American Association for the Study of Liver Diseases Practice Guidelines: the role of transjugular intrahepatic portosystemic shunt creation in the management of portal hypertension. J Vasc Interv Radiol. 2005 May;16(5):615-29.

[13] Komeda T, Fukuda Y, Sando T, Kita R, Furukawa M, Nishida $N$, et al. Sensitive detection of circulating hepatocellular carcinoma cells in peripheral venous blood. Cancer. 1995 May 1;75(9):2214-9.

[14]Liu Y, Zhang B, Qian G, Chen H, Wu M, Fu J, et al. [The detection of circulating hepatocellular carcinoma cells in peripheral venous blood by reverse transcriptionpolymerase chain reaction and its clinical significance]. Zhonghua Wai Ke Za Zhi. 1998 Oct;36(10):608-10.

[15] Giannini EG, Erroi V, Trevisani F. Effectiveness of alpha-fetoprotein for hepatocellular carcinoma surveillance: the return of the living-dead? Expert Rev Gastroenterol Hepatol. 2012 Aug;6(4):441-4.

[16] Brechot C, Gozuacik D, Murakami Y, Paterlini-Brechot P. Molecular bases for the development of hepatitis B virus (HBV)-related hepatocellular carcinoma (HCC). Semin Cancer Biol. 2000 Jun;10(3):211-31.

[17] Ruggeri M. Hepatocellular carcinoma: costeffectiveness of screening. A systematic review. Risk Manag Healthc Policy. 2012;5:49-54.

[18] Hann HW, Wan S, Myers RE, Hann RS, Xing J, Chen $\mathrm{B}$, et al. Comprehensive analysis of common serum liver enzymes as prospective predictors of hepatocellular carcinoma in HBV patients. PLoS One. 2012;7(10):e47687.

[19] Strasak AM, Rapp K, Brant LJ, Hilbe W, Gregory M, Oberaigner $\mathrm{W}$, et al. Association of gammaglutamyltransferase and risk of cancer incidence in men: a prospective study. Cancer Res. 2008 May 15;68(10):3970-7.

[20] Wannamethee G, Ebrahim S, Shaper AG. Gammaglutamyltransferase: determinants and association with mortality from ischemic heart disease and all causes. Am J Epidemiol. 1995 Oct 1;142(7):699-708.

[21] Mudawi HM. Epidemiology of viral hepatitis in Sudan. Clin Exp Gastroenterol. 2008;1:9-13.

[22] Mudawi HM, Smith HM, Rahoud SA, Fletcher IA, Babikir AM, Saeed OK, et al. Epidemiology of HCV infection in Gezira state of central Sudan. J Med Virol. 2007 Apr;79(4):383-5.

[23] Morgan TR, Mandayam S, Jamal MM. Alcohol and hepatocellular carcinoma. Gastroenterology. 2004 Nov;127(5 Suppl 1):S87-96.

[24] Montaser LM, Abbas OM, Saltah AM, Waked IA. Circulating AFP mRNA as a Possible Indicator of Hematogenous Spread of HCC Cells: A Possible Association with HBV Infection. J Egypt Natl Canc Inst. 2007 Mar;19(1):48-60. 


\section{International Journal of Science and Research (IJSR) \\ ISSN (Online): 2319-7064}

Index Copernicus Value (2013): 6.14 | Impact Factor (2015): 6.391

[25] Yang SZ, Dong JH, Li K, Zhang Y, Zhu J. Detection of AFPmRNA and melanoma antigen gene-1mRNA as markers of disseminated hepatocellular carcinoma cells in blood. Hepatobiliary Pancreat Dis Int. 2005 May;4(2):227-33.

[26] Bruix J, Sherman M, Llovet JM, Beaugrand M, Lencioni $\mathrm{R}$, Burroughs $\mathrm{AK}$, et al. Clinical management of hepatocellular carcinoma. Conclusions of the Barcelona2000 EASL conference. European Association for the Study of the Liver. J Hepatol. 2001 Sep;35(3):421-30.

[27] Nguyen MH, Garcia RT, Simpson PW, Wright TL, Keeffe EB. Racial differences in effectiveness of alphafetoprotein for diagnosis of hepatocellular carcinoma in hepatitis C virus cirrhosis. Hepatology. 2002 Aug;36(2):410-7.

[28] Okuda N, Nakao A, Takeda S, Oshima K, Kanazumi N, Nonami $\mathrm{T}$, et al. Clinical significance of alphafetoprotein mRNA during perioperative period in HCC. Hepatogastroenterology. 1999 Jan-Feb;46(25):381-6.

[29] Liu Y, Wu MC, Qian GX, Zhang BH. Nested RT-PCR in detection of blood AFPmRNA in animal model of human hepatocellular carcinoma. Hepatobiliary Pancreat Dis Int. 2003 Aug;2(3):414-7.

[30] Liu Y, Wu MC, Qian GX, Zhang BH. Detection of circulating hepatocellular carcinoma cells in peripheral venous blood by reverse transcription-polymerase chain reaction. Hepatobiliary Pancreat Dis Int. 2002 Feb;1(1):72-6.

[31]Jiang Y, Yang Z, Hu J. [AFP mRNA expression in peripheral blood correlates with metastasis of hepatocellular carcinoma]. Zhonghua Zhong Liu Za Zhi. 1999 Jan;21(1):38-41.

[32] Huang YK, Fan XG, Qiu F, Wang ZM. Combined detection of mRNA expression of Alpha-fetoprotein in peripheral blood and telomerase activity of monocytes in hepatocellular carcinoma patients. Hepatogastroenterology. 2013 Jan-Feb;60(121):1-5.

\section{Author Profile}

Ahmed Mohamedain Eltom Abdalla is Department of Biomedical Sciences, College of Medicine, King Faisal University, Saudi Arabia, Department of Biochemistry, Faculty of Medicine, Khartoum University, Sudan, P.O.Box 31982 